\title{
Drawing North America by Hand
}

\author{
Anton Thomas ${ }^{\text {a }}$ \\ a Anton Thomas Art, Melbourne, Australia; welcome@antonthomasart.com
}

\begin{abstract}
In February 2019, I put the finishing touches on a map that took four and a half years to complete. What began as a passion project ended up taking over my life, as I became utterly submerged in a cartographic odyssey: North America: Portrait of a Continent. Drawn entirely with colour pencil and fine-liner pen, this $1500 \times 1200 \mathrm{~mm}(59 \mathrm{x} 47$ inch) map contains tens of thousands of items of content, from the Arctic to Central America, even the deepest reaches of the ocean. 600 individualised cityscapes populate the map, and the content varies widely. All range of animals, plants, culture, history, industry, symbology, and more are laid out across a flowing terrain. It pulls from a vast sweep of the physical and cultural geography of the continent, and is intended to encourage geographic enthusiasm in a broad audience. Inspired by several years I spent travelling the continent, I'm finally able to reflect on it now it is complete. As prints begin to roll out, there is much to discuss about the origins, technical execution, intents and experiences of drawing North America by hand.
\end{abstract}

Keywords: Map Art, Cartography Art, Pictorial Map, Illustrated Map, Hand-Drawn

\section{Introduction}

Five years ago, I purchased a set of colour pencils and began drawing North America. State by state, city by city, I wanted to pay tribute to a continent. I envisioned a piece of map artwork that would capture continental complexity, that would revel in this grand theatre of geography and display it in a vivid and emotive way. Without any idea how long it could take, I stumbled into an odyssey of epic proportions. An odyssey that, after four and a half years and thousands of hours, is finally complete. North America: Portrait of a Continent.

Navajo sandstone and saguaro cactus, cotton-candy mountains of fall maple. Lady Liberty guarding the towers of Manhattan, frozen tundra stretching north to infinity. Mayan pyramids rising out of the jungle, eagles soaring across the Rocky Mountains, a sweep of boreal forest half the size of Europe. I describe a mere fraction of the wonders of this place. North America has a magnificent geography and expressing this with cartographic art struck me as an excellent way to tell that story.

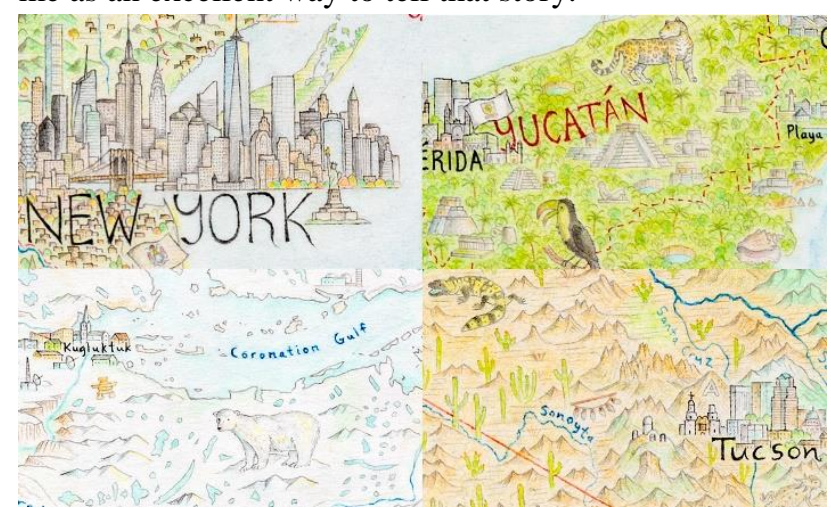

Fig. 1. A montage of varying North American content.

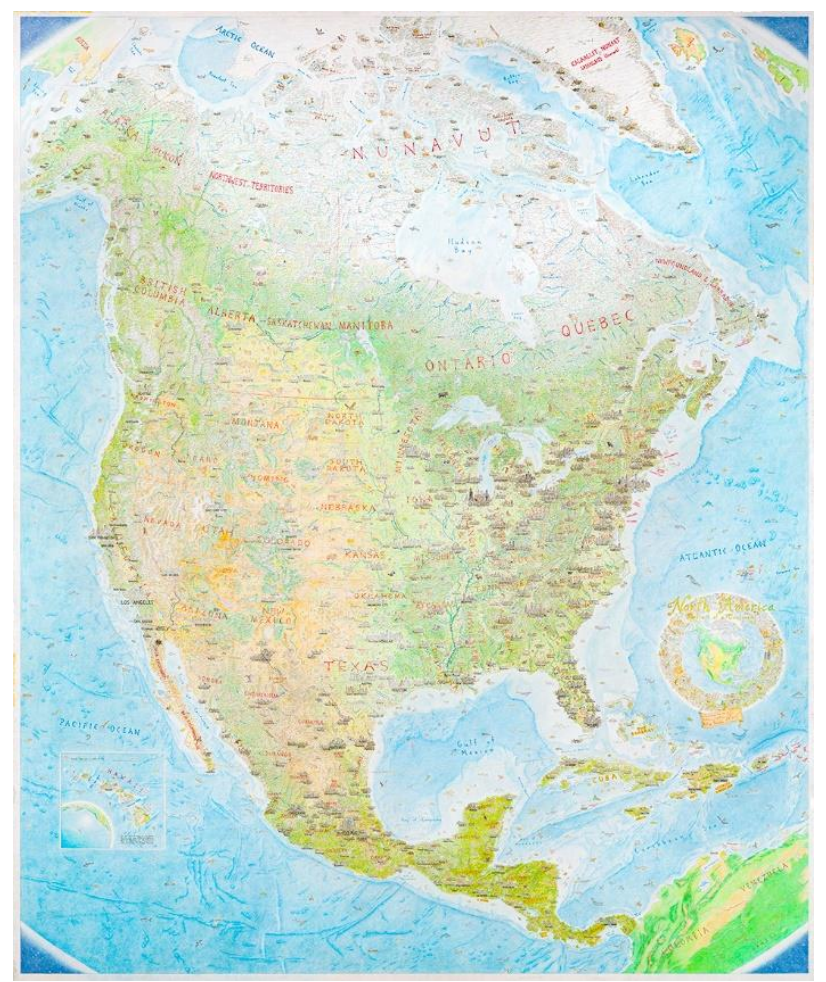

Fig. 2. The entire map, North America: Portrait of a Continent.

\section{Origins}

The continent first enchanted me in 2011, when I arrived as an impressionable 21-year-old fresh out of New Zealand. My first trip overseas, a one-way ticket to California led to two years living across the U.S. and Canada. As a map-obsessed geography fanatic I marvelled at the scale and variety of the place. The vast dimensions of a continent were something new to me, and this new view was expansive and inspiring. It called me to adventure, just as maps always had when I was a child. 
This sense of geographic awe was not always present in others. Many people had travelled little of their country, and seemed either unaware of its majesty, or so overwhelmed by its size that thinking about it was exhausting. Being from New Zealand, a nation small in both land area and population, I knew I was experiencing continental scale as a novelty. I didn't expect people to see the grand frontier right there at home, and a foreigner's perspective differs from the local whose life - with all its ups and downs - is inseparable from the place. But I felt North America was a masterpiece of geography, and I wondered how I might present this to others. Perhaps in doing so effectively, geographic curiosity could be encouraged in a wider population.

A grasp of geography is important. It expands our understanding of the world and our place in it. How important is setting to any story? So central you can forget it's even there. Contemplating the roles that setting and place play in the character of our lives is immensely valuable. It promotes metacognition. It motivates us toward adventure, and away from needless boredom. After all, this world contains more mystery, treachery and magic than any fantasy land conjured up by the greatest minds of fiction. So, I began to envision an illustrated map that would simultaneously capture the viewers imagination while teaching them geography. A map that would kick the door wide open for content, let in the animals, the flowers, even the sounds and smells. A map that would show every city as the unique place that it is.

As my North America travels progressed, I began to reconnect with two things that obsessed me as a child. Maps, and drawing. I would pass the hours on long train and bus rides by practicing drawing the USA. I carried a range of maps collected from my journeys, putting Unique Media's pictorial map of the US up on the wall every time I rented a room. The more I travelled the continent, the more I imagined its remarkable geography expressed in a huge pictorial map.

\subsection{The refrigerator}

Toward the end of my two years there, while living in Montréal, my housemate Douglas suggested I draw something at the house before I left. He had noticed I had some talent for drawing and encouraged me to create a piece of art for the apartment. While considering a canvas for this memento, I noticed he had recently refreshed our tired, stained old fridge with a coat of white house paint. Something intrigued me about the clean white expanse of its freshly painted doors. I saw the canvas I needed. Without much thought to the challenges a fridge might pose, I picked up a black pen and began to draw that which had obsessed me since I arrived. I began to draw a map of North America.

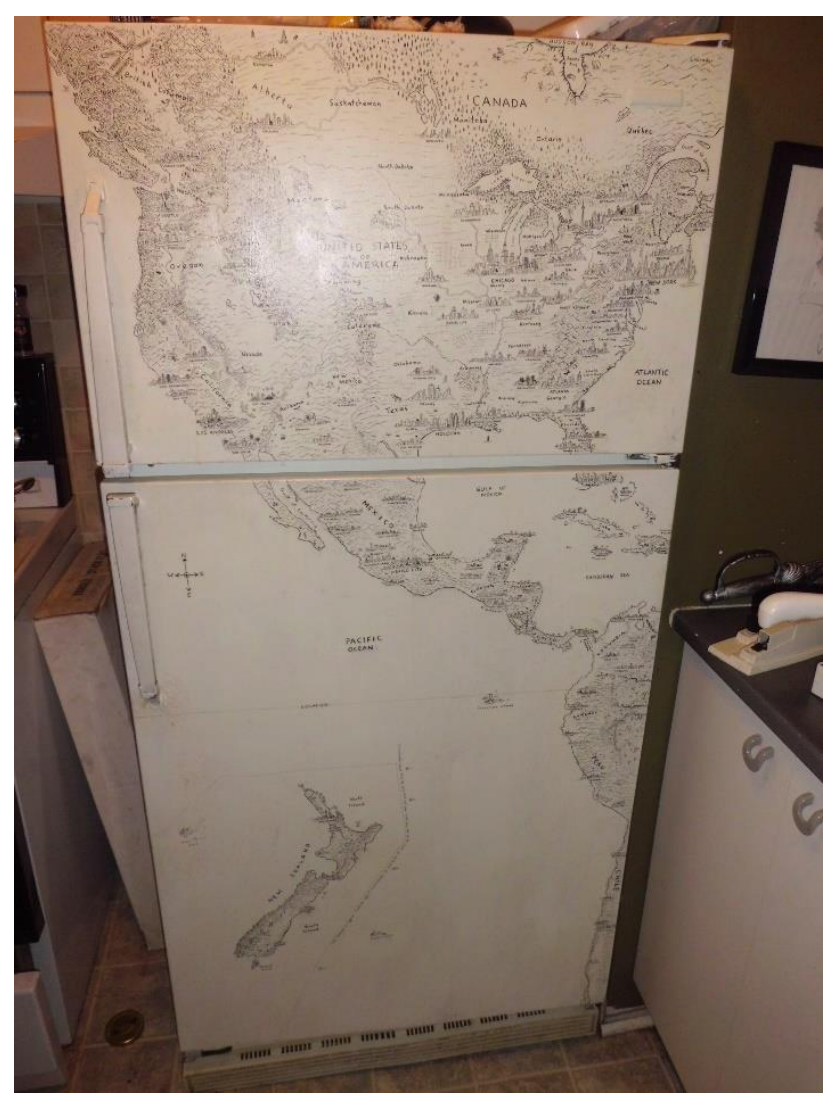

Fig. 3. The fridge map from Montréal that began it all. An inset map of New Zealand signals home. The inset has text explaining that NZ's correct location would be on the oven door.

Over a month passed and I finally finished, having been glued to the fridge the whole time. It was a tricky canvas indeed, as the old appliance was filled with food, actively in use every day, next to a sink. But I found the process to be an absolute revelation. The map was totally freehand, and it was crude, but I could see a style developing and my skills improving. Not only did I love every second of the research and the execution, but other people seemed to like it too. Visitors to our house would find themselves lost perusing cartographic detail on a fridge door. I swore that as soon as I was next settled, I would explore this idea in greater depth.

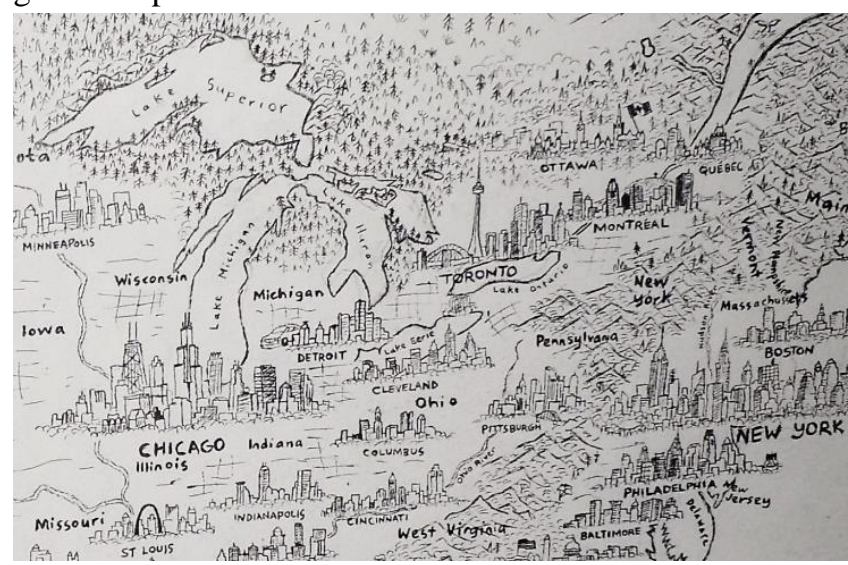

Fig. 4. Close-up on the fridge map. 


\subsection{South Asia and Australasia}

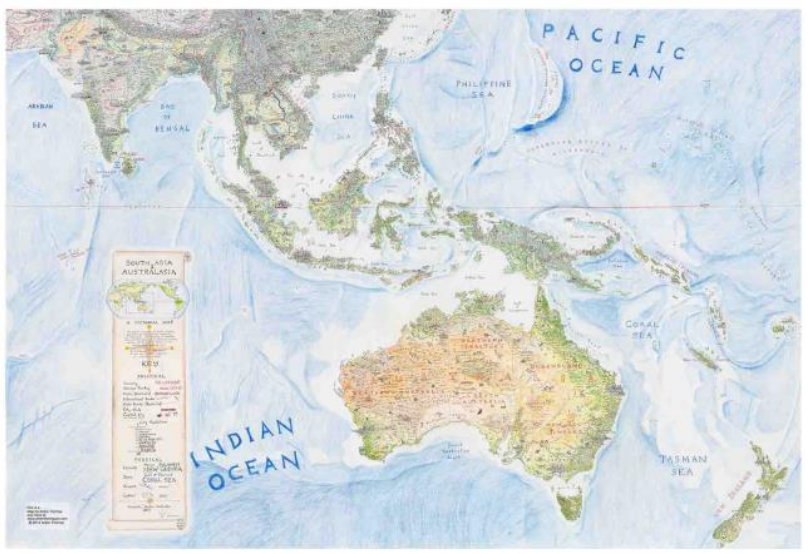

Fig. 5. South Asia \& Australasia (2013).

That chance came the following year, when I moved to Perth, Australia. As soon as I landed, I began drawing a map that would take six months to complete: South Asia \& Australasia. The map spans a huge swath of the world, from Pakistan to New Zealand. Building on all I had learned from the fridge, I began to develop my abilities further with colour pencil. I set the map up in my bedroom and poured hours into it every day after work. Slowly but surely it progressed, from northwest to southeast, from the world's mostly densely populated regions to the Australian Outback. India, China, Southeast Asia, Indonesia, finally to Australia and New Zealand. I gained thousands of hours of experience and my abilities were taken to a new level.

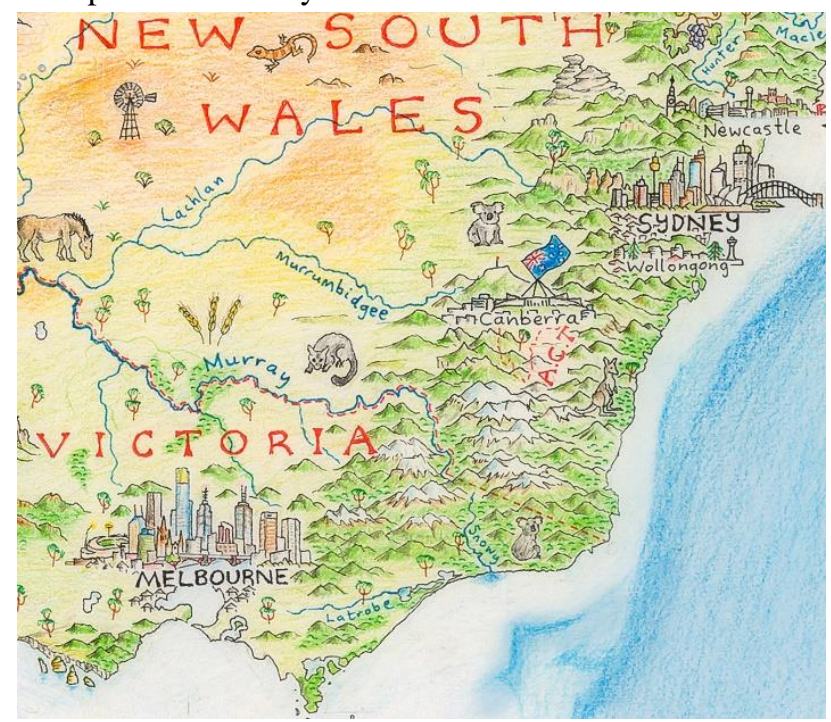

Fig. 6. An Australian close-up from South Asia \& Australasia.

\section{North America begins}

The following year I relocated to Melbourne. Now it is May of 2014. Having learned so much from South Asia \& Australasia, I decided to commence a new journey across North America. No household appliances this time, I was going to draw the continent properly. Clipping a $150 \mathrm{x}$ $120 \mathrm{~cm}(59 \times 47 \mathrm{inch})$ square of art paper to a piece of MDF, I used a projector to shine onto it a map of the continent. With this I traced out the coastlines, political borders and more. This base pencil outline was the critical skeleton I needed to guarantee a broad level of accuracy across the map. With this, I could begin.

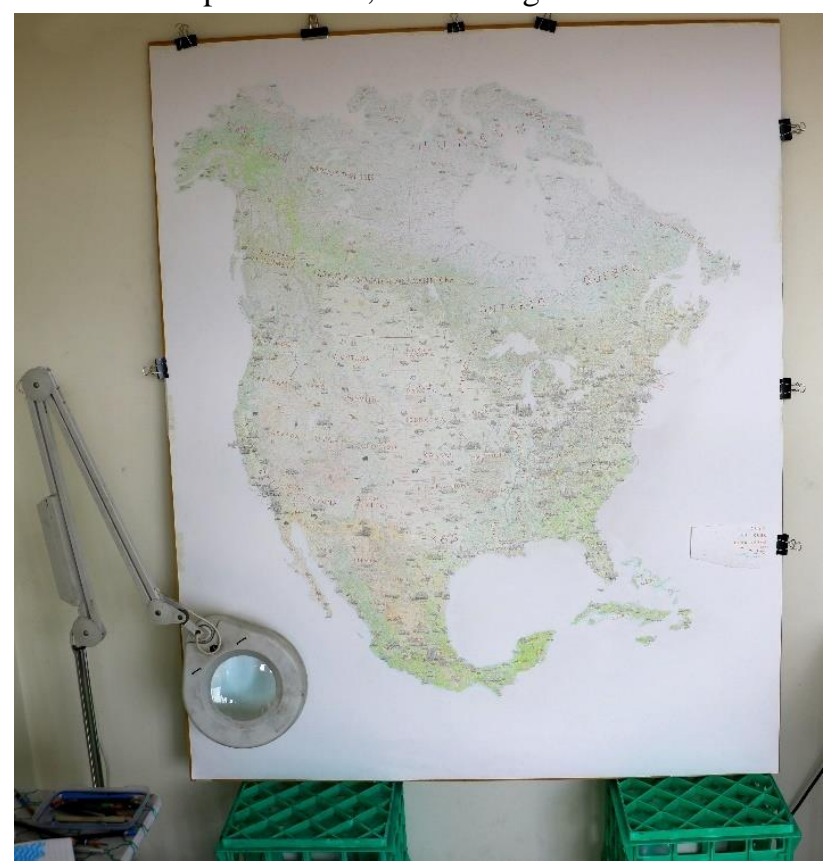

Fig. 7. The map underway in my home studio, showing the magnifying lamp that was used to draw the detail (2016).

I opted for Google Earth's rendition of the continent, a perspective projection. While initially I wanted an equal area projection, Alaska's enormous size and northwest protrusion caused a dramatic expansion of the ocean. It took in far more of the North Pacific than was desirable, while reducing the size of the rest of the continent. Instead I chose the Google Earth perspective which reduces Alaska's size, as all four corners curve away to the edge of the Earth. I liked this for more than just scale and positioning. I felt the curved projection would give the map an attractive composition, creating artistic opportunities I could utilise well with my style of illustration. And it allowed me to set the map in the stars, as I stencilled out specific constellations for each corner, adding value and meaning to the far margins of the piece.

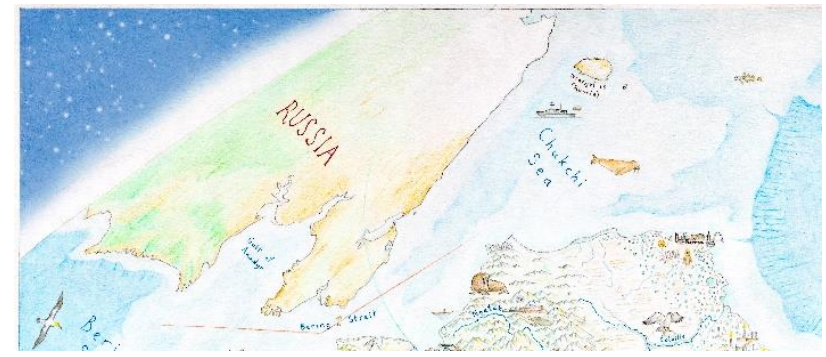

Fig. 8. The northwest corner, showing the constellations of Ursa Major and Ursa Minor, which contains Polaris (the North Star). These are universal symbols of the far north, with Ursa Major and Polaris both on the flag of Alaska.

It is worth noting that all of this was started without professional training. I had my abilities garnered from a lifelong passion for maps and drawing, but these were talents I'd only truly begun refining 18 months earlier with the fridge map. This was started out of curiosity, rather than with a commercial plan in mind. What I was commencing was something I only faintly understood, and 
which I did not have the skills to complete at the outset. But I was about to get all the training I needed, as this new project would come to define the next four and a half years of my life.

The guidelines were few outside of ensuring it was all as accurate as possible. In every corner of the continent, I'd research heavily in search of content that might evoke a feeling of place. Content that would be familiar to a local. Fauna, flora, agriculture, industry, symbology, history, music, oddities, whatever it might be, all flowing across terrain faithfully drawn. I drew individualised cityscapes for every city that would fit with a metropolitan population greater than 100,000, while in the Arctic and sub-Arctic I lowered this to only 1,000 to correct for a smaller population. There are exactly 600 cities and towns featured across the project, from Los Angeles, California to Pangnirtung, Nunavut.

\section{Drawing}

The map was drawn with Derwent Studio colour pencils, Staedtler Mars Lumograph grey lead pencils (particularly hard leads like $6 \mathrm{H}$ and $7 \mathrm{H}$ ), and a variety of pigment ink fine-liner pens. The pens were mostly for labels, political borders and rivers, with pencils used for everything else. Early on I used pen to outline buildings and animals, but pen is permanent and risky, and I like to minimise risk where I can (investing thousands of hours into one piece of paper is a vulnerable way to live). A magnifying lamp allowed me to draw at very small sizes, enabling a vast level of detail. Tools acquired during the drawing helped me to execute the diverse array of challenges, including a variety of rulers, levels, flexible curves, French curves, as well as exacto knives, sandpaper for sharpening, an electric eraser, eraser guard, a headset magnifier, even an air blower hand-pump for careful dispersion of eraser shavings.

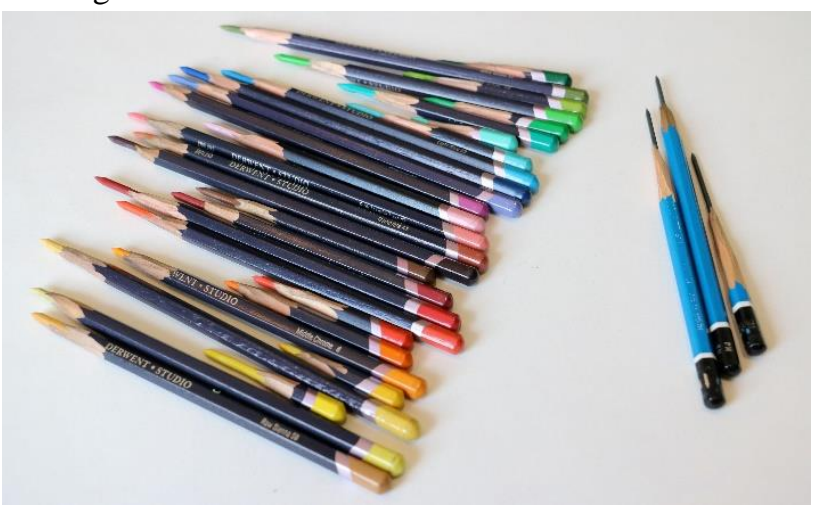

Fig. 9. A selection of heavily sharpened pencils used for the map. The first thing I drew was Vancouver. Being right-handed, I work from left to right to avoid my hand resting on completed artwork, so it needed a western starting point. And having lived in Vancouver in 2012, it was a city and region I knew well. First-hand experience with where I'm drawing always offers a head-start, although the research is intensive regardless. It is hard to know exactly, but I estimate the research was at least $40 \%$ of the overall labour of the map. With every region, every country, state, province and city, I read all I can online about it to try and get a sense of its defining features and characteristics. I'll take plentiful notes as I trawl through endless Wikipedia pages, photos, maps, travel sites, blogs, news articles, obscure websites, even listening to music from the region itself to try and get into its zone.

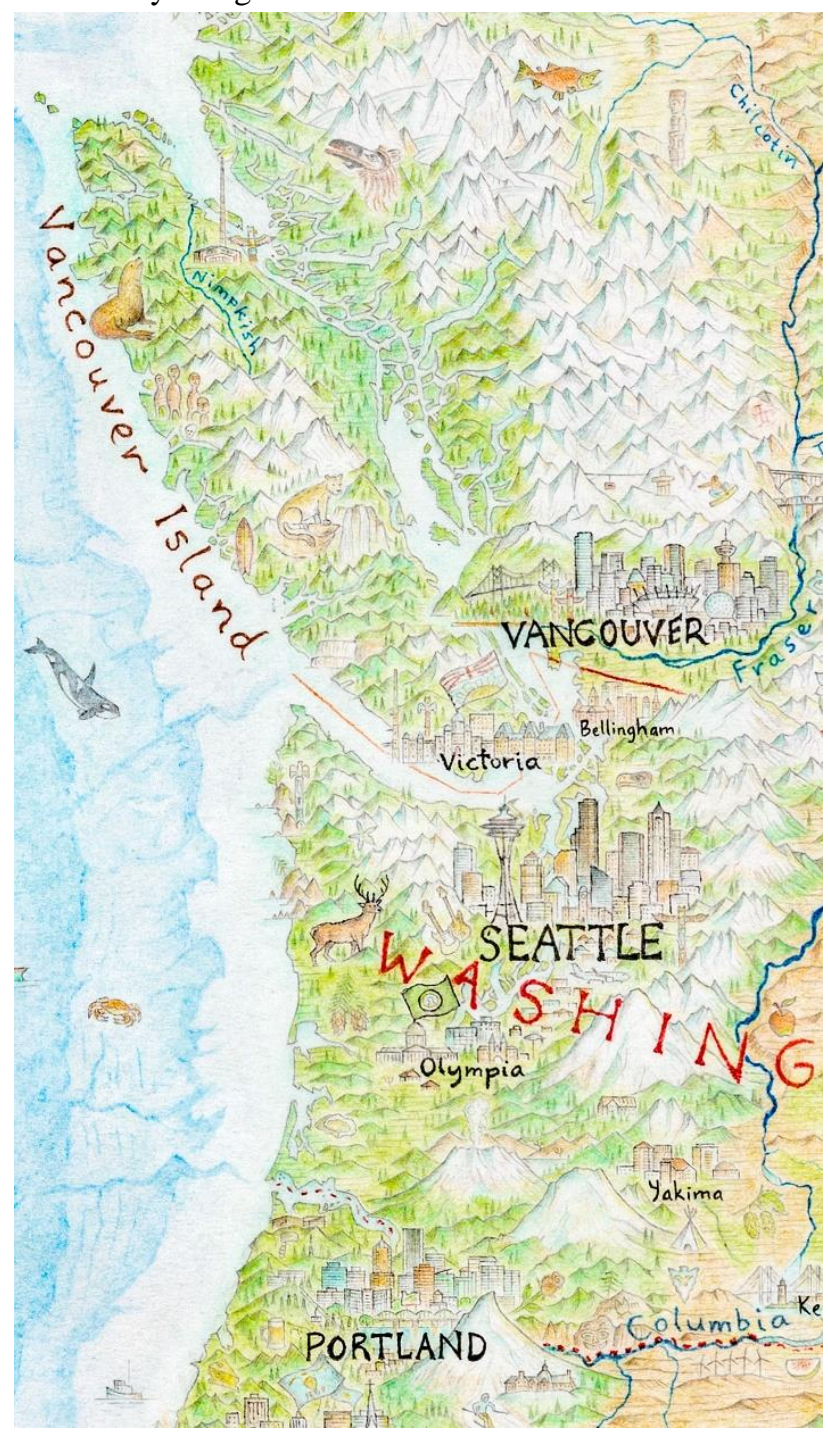

Fig. 10. Part of the Pacific Northwest, the first area drawn on the map.

Making this map was an endless series of decisions about what to omit and what to include. The physical geography is the right place to start of course, with rivers, relief and land use providing the backdrop for everything. I tend to draw state by state (province/territory in Canada), with broad research sessions inaugurating the drawing of each entity. For example, I'd start by reading all I could about Texas, marking off the basics as I went (cities, rivers, labels, national parks, mountains, anything particular that comes up). Then I'd focus in on West Texas, or wherever I was drawing first, and read more. In some areas I would even focus at the county level as I hunted for localised, targeted content. The research and prep were all about these different layers of investigation, which would continue until I was ready to start drawing. The pre-drawn area would be covered in pencil notes, and I'd have many sites located and pinned on Google Earth. 


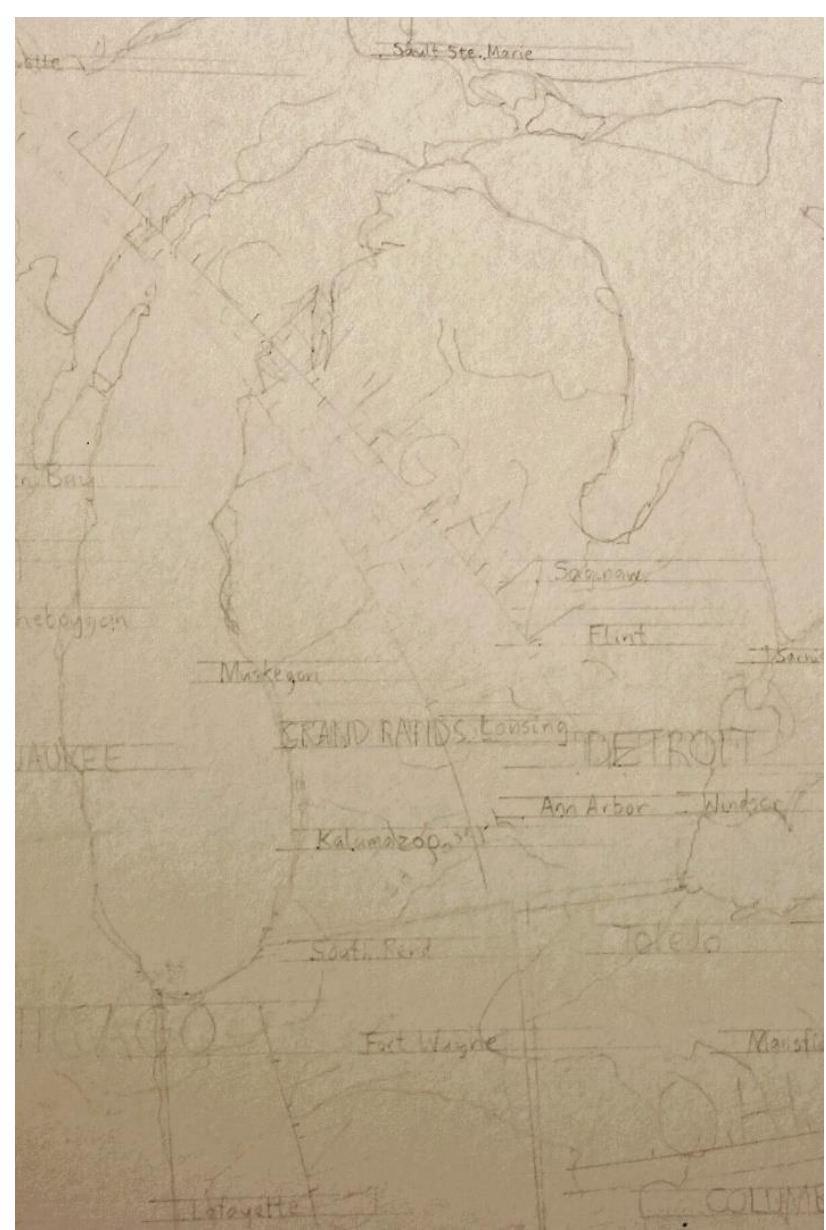

Fig. 11. A region of the Midwest showing pre-drawing label prep. City labels are ruled out with a spirit level.

Locations of chosen cities were quarantined, as each of these were mini-research projects by themselves. Once located, I would rule up their labels with a level to keep them flush with each other, with the size and style of each label determining the population grade. For example, cities with capitalised labels have more than one million people. Over three million and the label gets two millimetres taller. Every one of the 600 cities and towns required hours of work, each with their own unique challenges. Some cities have clear, iconic skylines, while some don't have a single tall building. Each time I had to construct a cityscape out of its landmarks - as well as culture, heritage and economy - and do so with care and patience. After all, these are real places. When you're making art out of people's homes, you must do so with humility and curiosity. It is precious cargo you are handling, material that is woven into people's lives.

Sometimes, the decisions are obvious. Of course, New York will have the Empire State Building. San Francisco will have the Golden Gate Bridge. There is the Grand Canyon. Niagara Falls. Chichén Itzá in the Yucatán. Cards and dice in Las Vegas. A trumpet in New Orleans. Some animals are obvious, too. A grizzly bear in northwest Montana. A polar bear at Churchill, Manitoba. Longhorn cattle in Texas. On it goes. Some things are iconic for a reason, and they are a sure bet for inclusion.
But at other times I could spend hours just looking for clues. As every place is different, the experience of learning about and drawing it is completely different too. Researching New York City is nothing like researching Baffin Island. So as the map progressed, I was challenged with a continental level of diversity. This was a deeply enriching experience, during both research and technical execution. As months turned into years, I was honing my skills on everything from skyscrapers to tornadoes, bison to jellyfish, totem poles to sea ice. One month I'd be immersed in Cuba, the next would be all about the Yukon.

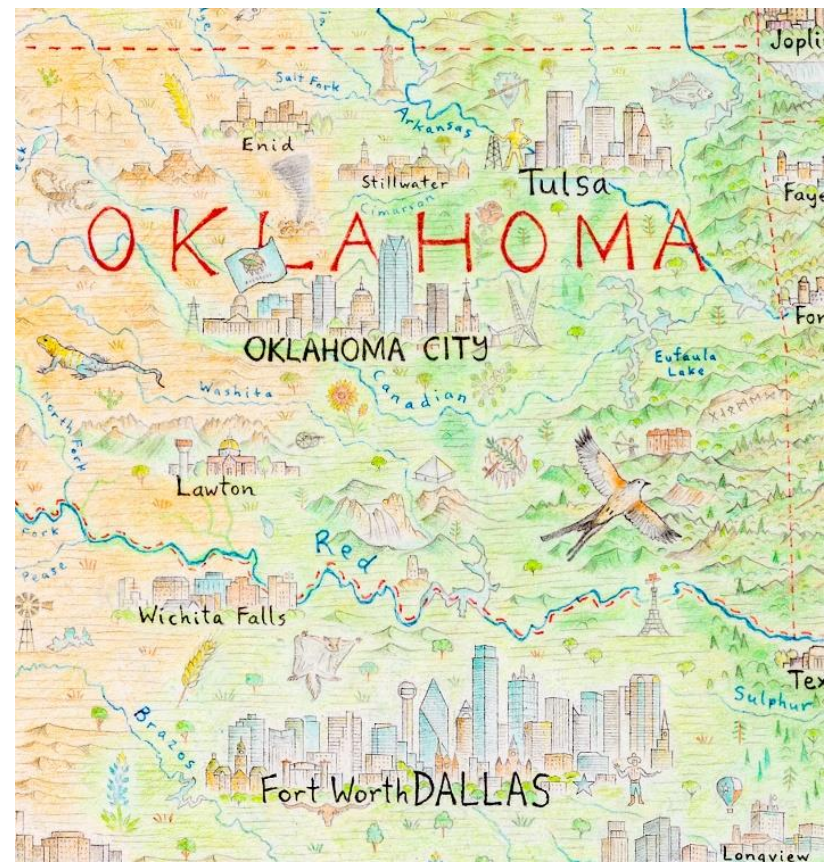

Fig. 12. Oklahoma and North Texas.

It was always going to be a big job, but if I had known back in 2014 it would take nearly five years to complete, I would have laughed at the idea. I initially guessed it would take six months. As the years went by, my shock at the enormity of this self-assigned task slowly hardened into a grizzled determination. A resolute belief that one day I would finish and be released from its spell.

Things got particularly gruelling in early 2017. After almost three years, I finally completed all the land of the map, and should have been ready to start the ocean. But the thousands of hours of practice I gained hand-drawing the map were really showing. A vast technical and stylistic gulf had opened between old and new content, and I decided to go back and make improvements to the early stuff. Essentially, I went right back to the start. All the way to Vancouver. I had used a lot of pen in the earliest areas, so I assumed I would be limited in what I could fix. But I quickly developed a slow, harrowing technique of scratching pen off paper with my exacto knife, and was able to transform and re-draw anything I wanted to. In the end I spent thousands of hours re-drawing the western half of the USA, and the western third of Canada. This added fifteen long months to the project, but it was worth it. 


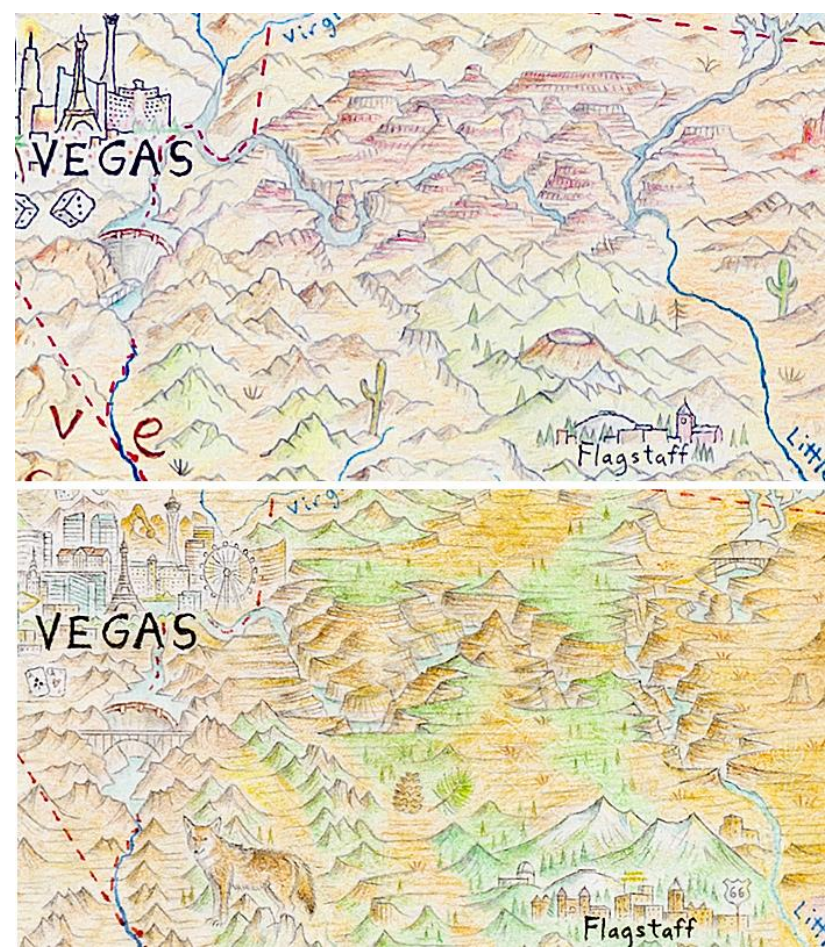

Fig. 13. The Grand Canyon region before and after the western re-drawn. 2014 on top, 2018 on the bottom.

\section{Final stages}

The re-draw ended in mid-2018, and I was able to commence with the final stages. First the ocean, with a bathymetric relief I created using five specific layers of blue pencils smoothed out with a paper stump. Many hundreds of sea creatures, seabirds, ships and boats can be found across the oceans, as well as the Arctic ice cap at its 2017 summer minimum. Three of the four corners include land outside of North America, and I drew them in a lowresolution style without any content. These include Chukotka (Russia), Iceland, Ireland, the U.K, Colombia and Venezuela. Also, an inset map of Hawaii was drawn in the tropical Pacific to complete all 50 United States.

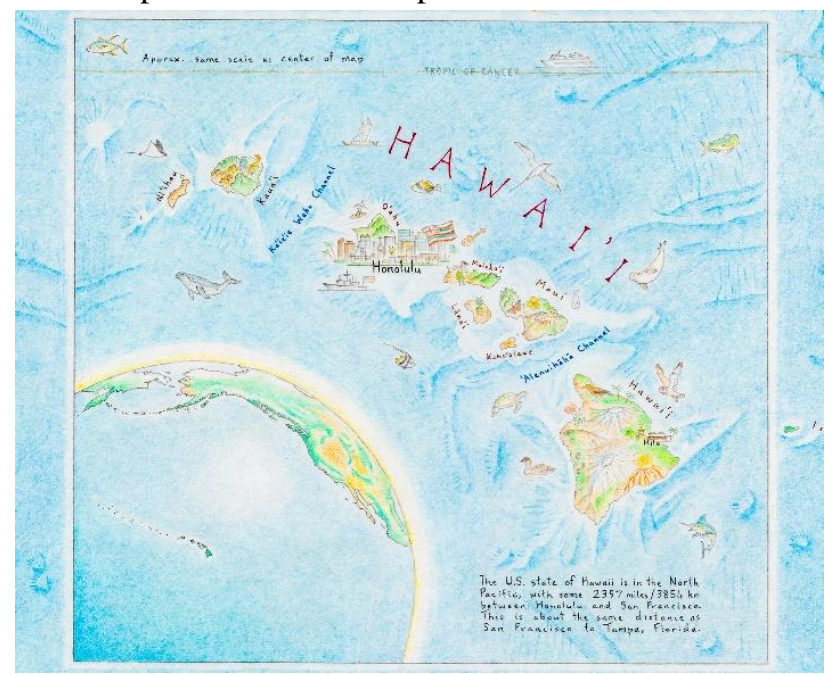

Fig. 14. The inset map of Hawaii, complete with locator globe. The text at the bottom-right states the distance from San Francisco to Honolulu, explaining this is the same as San Francisco to Tampa. This affords the viewer a visual reference for the distance using the main map.

\subsection{Cartouche}

The very last thing was the map's cartouche, which I drew in January of 2019. Placed in the Bermuda triangle, it took more hours to complete than some stand-alone commissions maps I've drawn. Given the scale and complexity of the entire project, I felt that the cartouche had to do it justice. It must be intricate. I wanted to create an emblematic design, a bold symbol of the map that showcases the kind of content one will find in its details. There was no need for a key on this map, and both orientation and scale vary due to the perspective projection. All I needed was a place for the title, and somewhere to sign and date it.

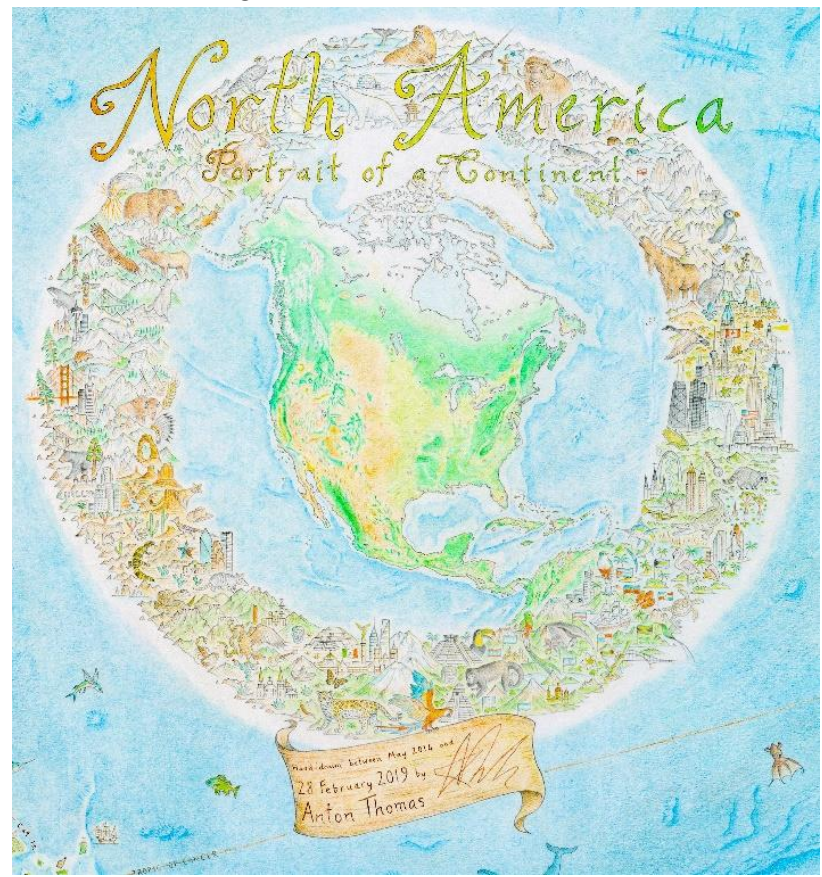

Fig. 15. The cartouche.

North America: Portrait of a Continent sits across the top, with a shifting colour grade of Earth tones. The design of the cartouche is to be just that: a portrait of North America. A mini-map of the exact same projection is surrounded by a frame of dense detail. Rather than the labyrinthine content of the map proper, the cartouche map allows North America to be nothing but its pure geography. Coastlines, land cover, a touch of relief, the grey sprawls of major urban areas, and bathymetry. Meanwhile the "frame" of the portrait is where all the action is. A phantasmagoria of iconic North America encircles the mini-map, a summary of the project containing some of the continent's most recognisable features. They are positioned relative to their location. From the iconic eagle-and-snake of the Mexican coat of arms, to the North Star and inuksuk from Nunavut's flag, the frame is filled with symbolism. It is as densely detailed as the richest parts of the map itself, hosting more than 50 animals, as well as buildings from dozens of different cities. 


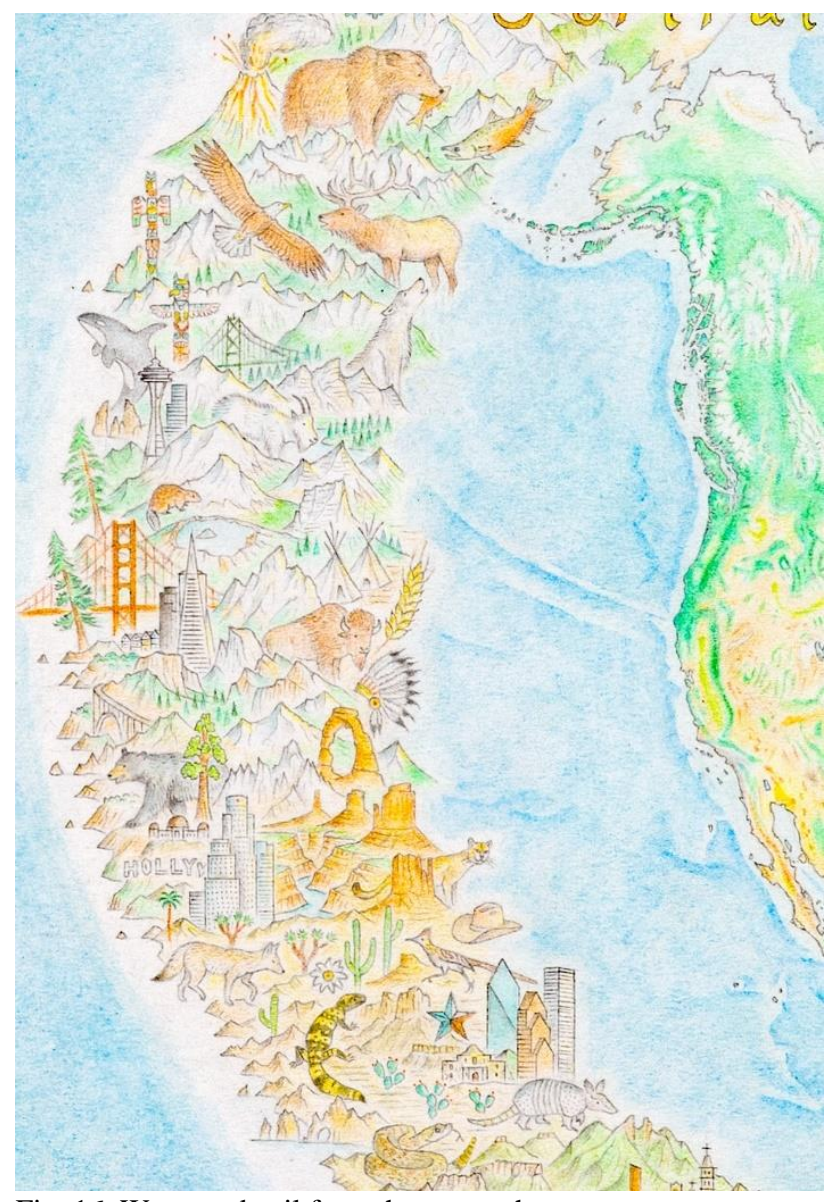

Fig. 16. Western detail from the cartouche.

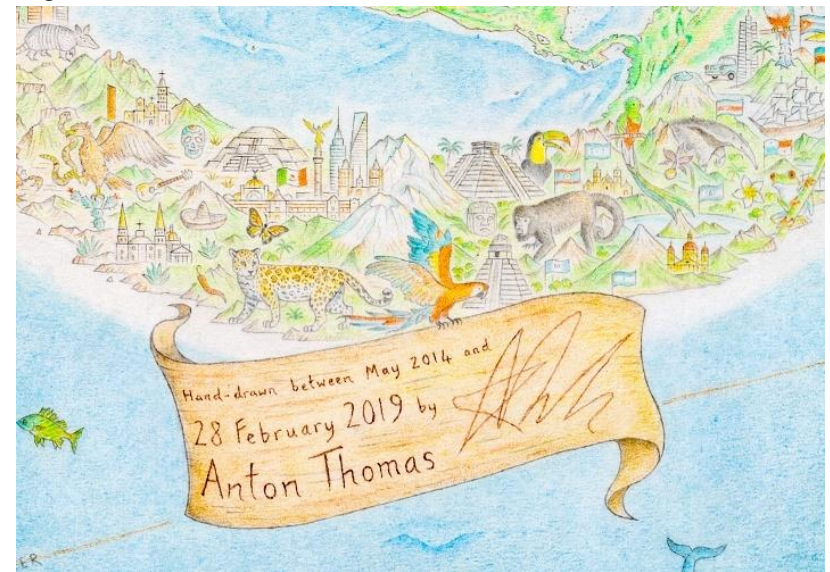

Fig. 17. The bottom edge of the cartouche, showing the sign-off scroll held by a scarlet macaw.

Flags of every sovereign nation on the map can be found in the frame, particularly dense with Central America and the Caribbean. At the bottom, a scarlet macaw holds a banner that contains some basic details. I considered many options, but in the end kept it simple with just my name, signature, when it was made, and that it was hand-drawn. Who, when, and how. This banner is the only time my name appears on the map, and I drew it held up by a macaw in order to suggest that it is the content that runs the show. I am lost without it. I was able to make the map because the world is so interesting. That is why it works, and that is why I drew it.

\subsection{Completion}

I signed it off on February 28, 2019, in an emotional final session. With this odyssey now complete, I feel energised. Never could I have made it through the endless hours if I thought I wouldn't see it done. I worked a day job during the first three years, so often I was drawing at night, on weekends and holidays. Since early 2018 I have worked full-time on my cartography, but it became an obsession long before this. Drawing it relentlessly, being at home in my studio all the time, day and night, it was challenging. Sometimes I felt I was going mad, just stalking around in my own mind. All else became a distraction, a nuisance. There was only this giant map that would never end. And my house. And my mind. Podcasts, audiobooks and music helped a lot, but always I had to be there putting those hours in.

Yet the map was also my portal out. Out of my mind. Out of the house. Out of the street. Out into the wider world. Not just professionally, but psychologically. The map became my portal to elsewhere. To somewhere. Drawing it became a sacred ritual. It became the lion and the witch in my wardrobe. And to finish it became the one goal that overrode everything else in my life until it was done. Of course, my journey with it continues as I release prints to the world, and I will get to resume that sacred ritual with my next map. But it is hard to overstate the elation that I feel to have finally finished this.

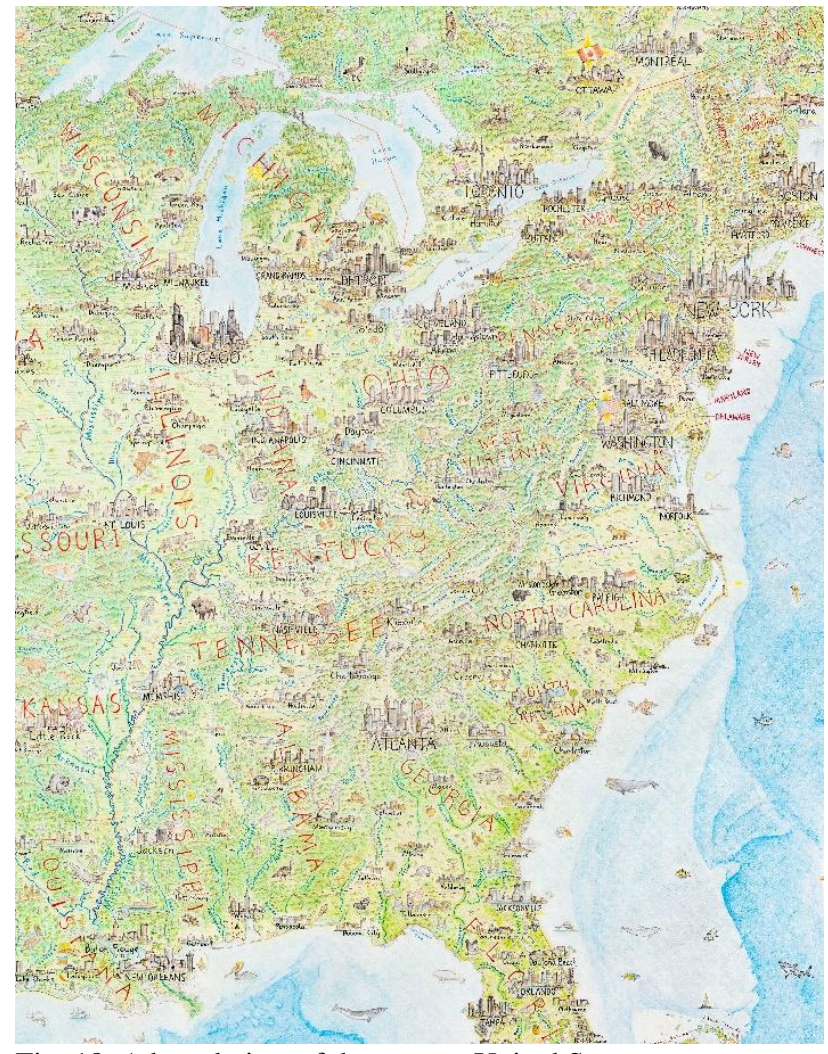

Fig. 18. A broad view of the eastern United States. 


\section{Conclusion}

North America: Portrait of a Continent is an illustrated map of broad dimensions, a love letter to a land of incredible variety. It is a hand-crafted study of a continent that attempts to marry art with cartography, using the strengths of either discipline to tell a story that anyone is compelled to read, regardless of their individual interest in geography or maps. Cartography is unusually artistic for such a technical discipline, and with the data source being our beautiful planet, it is limitless in what it can display. Best of all, nothing needs to be fabricated. Just pick from the content present in the physical and cultural geography and exhibit genuine interest in each place. Respect the place. Alongside technical proficiency this will always lead to beautiful map art, wherever you may be focussing on.

As I present to the world this map of North America, I'm still trying to figure out exactly what it is. After all, the vastness of the detail and hours spent on it were unexpected, however welcome. I was under its spell for so long that I'm still just trying to take stock. But I look forward to unpacking it in presentations, sharing the story, taking people on tours of it, and finding out what others discover as they become familiar with their prints. Most of all, I can't wait to make many more maps. They don't have to take anywhere near this long. And, rest assured, there will be no scratching off pen with a knife next time.

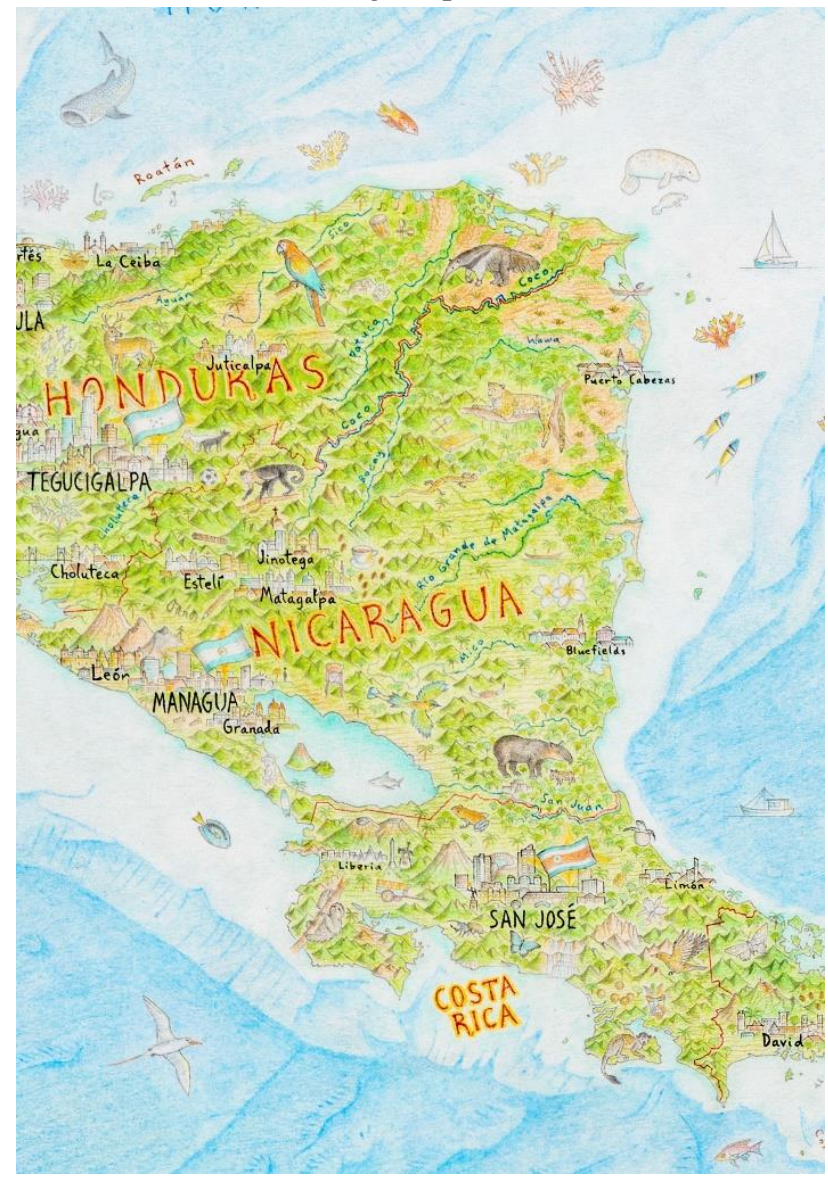

Fig. 19. Part of Central America. 